\title{
Article
}

\section{Assisting the Investigation of Stranger Rapes: Predicting the Criminal Record of U.K. Stranger Rapists From Their Crime Scene Behaviors}

Almond, Louise, Mcmanus, Michelle Ann, Bal, Amarat, O'Brien, Freya, Rainbow, Lee and Webb, Mark

Available at http://clok.uclan.ac.uk/21654/

Almond, Louise, Mcmanus, Michelle Ann ORCID: 0000-0002-0095-1071, Bal, Amarat, O'Brien, Freya, Rainbow, Lee and Webb, Mark (2018) Assisting the Investigation of Stranger Rapes: Predicting the Criminal Record of U.K.

Stranger Rapists From Their Crime Scene Behaviors. Journal of Interpersonal Violence. ISSN 0886-2605

It is advisable to refer to the publisher's version if you intend to cite from the work. http://dx.doi.org/10.1177/0886260518756118

For more information about UCLan's research in this area go to http://www.uclan.ac.uk/researchgroups/ and search for < name of research Group>.

For information about Research generally at UCLan please go to http://www.uclan.ac.uk/research/

All outputs in CLoK are protected by Intellectual Property Rights law, including Copyright law. Copyright, IPR and Moral Rights for the works on this site are retained by the individual authors and/or other copyright owners. Terms and conditions for use of this material are defined in the policies page. 


\section{Assisting the investigation of stranger rapes: Predicting the Criminal Record of UK stranger rapists from their Crime Scene Behaviors.}

\section{Dr Louise Almond}

School of Psychology, University of Liverpool, Eleanor Rathbone Building, Bedford Street South, L69 7ZA, email: lalmond@liverpool.ac.uk tel: 0044 (0)151 7946708

Dr Michelle McManus1

Policing and Criminal Investigation, School of Forensic and Applied Science, University of Central Lancashire, Preston, PR1 2HE, email: mamcmanus@uclan.ac.uk tel:

$0044(0) 1772894154$

\section{Amarat Bal}

School of Psychology, University of Liverpool, Eleanor Rathbone Building, Bedford Street South, L69 7ZA, email: amaratbal@hotmail.com

Dr. Freya O'Brien

School of Psychology, University of Liverpool, Eleanor Rathbone Building, Bedford Street South, L69 7ZA. F.Obrien@liverpool.ac.uk

Mr Lee Rainbow

National Crime Agency, London, UK. Lee.Rainbow@nca.x.gsi.gov.uk

Mr Mark Webb

National Crime Agency, London, UK. Mark.Webb@nca.x.gsi.gov.uk

\section{Introduction}

Current police investigation methods used within the United Kingdom (UK) for serious, unsolved crimes have combined research and practitioner experience through the use of Behavioral Investigative Advisors (BIAs) who provide investigative support and advice to serious unsolved cases. The importance of providing "adequate scientific support" (Alison, Goodwill \& Alison, 2005, p.235) in claims made by BIA's has been highlighted, with much reliance now stemming from empirical research using investigative policing data. The current study seeks to explore the 
validity of the findings by Davies et al. (1997) within their study predicting stranger sexual offender criminal history from crime scene behaviors, with a contemporary sample. The findings from the Davies et al. study were, and have been used, by BIAs in assisting rape investigations. Due to the time period since implementation of the findings, a contemporary replication was undertaken to assess the validity of the findings and explore any changes in behaviors of stranger rapists within the UK.

Statistics published by the Ministry of Justice (2013) reported that around 97,000 individuals are raped each year in the UK, 87 percent of whom are women. Following homicide, rape is considered to be one of the most serious criminal offences (Home Office, 2007). As a result, rape is a widely researched and debated topic, particularly for those working within the forensic sphere (Dowden, Bennell \& Bloomfield, 2007). According to the Ministry of Justice (2013), 10\% of sexual assaults against a female are committed by a stranger. Stranger rape cases can be particularly difficult to solve; physical evidence to aid investigative inferences is often lacking, with sometimes only the account provided by the victim available to investigators (Corovic, Christianson \& Bergman, 2012; Ter Beek, Van Den Eshof \& Mali, 2010; Scott, Lambie, Henwood \& Lamb, 2006). Furthermore, investigators frequently work under considerable time pressures to apprehend the offender, with limited resources available to them, making offender apprehension even more challenging (Hakkanen, Lindlof \& Santilla, 2004).

Recent UK figures released by the Office for National Statistics (ONS, 2017), has revealed a rise in police recorded sexual offences. The data indicated a $19 \%$ increase in sexual offences in June 2017 from the previous year (July 2015 to June 2016), rising from 109,093 to 129,700 cases. For rape, this increased by $22 \%$ from 36,829 to 45,100 offences. However, it was noted that $25 \%$ of the $2016-2017$ figures 
were related to 'non-recent' offences (incident did not occur within last 12 months of crime being recorded). In serious sexual assaults committed against females, 16\% were recorded as 'stranger relationships' (ONS, 2015). The most recent figures from the ONS (2017) found $14 \%$ of rapes identified a stranger as the suspect. However, they do further note that $46 \%$ of rape suspects were known acquaintances, with $40 \%$ recorded as unknown relationship, due to a suspect not being identified. This high rate of unknown relationship, raises questions regarding the recording of sexual offences generally, this has been raised within the recent Her Majesty's Inspectorate Constabulary (HMIC, 2014) report where 1 in 4 sexual offences which should have been recorded by police forces, were not. In light of these figures, there is increasing emphasis on gathering information to further understand sexual offending, including stranger rapes in order to develop pragmatic and relevant methods that will improve investigative success (Newman, 2011).

\section{Offender profiling}

The central framework of offender profiling is known as the A to C equation, whereby crime scene actions (A) are used to make inferences about the background characteristics of an unknown offender (C) (Canter, Bennell, Alison \& Reddy, 2003). The profiling equation rests on the prominent assumption of homology (Mokros \& Alison, 2002), which states that offenders who commit crimes in a similar manner and exhibit similar crime scene behaviors will share similar background characteristics (Petherick \& Ferguson, 2013). Being able to make logical inferences of an unknown offender's background would be of great investigative utility, providing 
directly useful information to aid the investigative process, particularly potential nominal prioritization (Ter Beek et al., 2010; Scott et al., 2006;).

The vast majority of sexual offenders have criminal antecedents; previous research suggests that around $84 \%$ of stranger rapists have previous convictions (Davies, Wittebrood \& Jackson, 1997). These offenders, therefore, are already recorded in the system (Alison et al., 2010). Thus, criminal history profiling has the potential to be a powerful investigative tool (Scott et al., 2006). Any behavioral advice given must be based on reliable and evidence-based research; claims based on unreliable research can have disastrous investigative consequences (Lundrigan \& Mueller- Johnson, 2013). Therefore, in order to inform forensic practice, psychologists have examined the relationship between crime scene behaviors and offender criminal history.

There is considerable debate within the sphere of investigative psychology as to the most appropriate approach to examine associations between crime scene behaviors and offender characteristics (Alison et al., 2010). Some researchers have favored using simple bivariate associations to investigate associations between offence behaviors and criminal history, whereas others have adopted a thematic approach, which looks at clusters of behavior and how these relate to general background themes (Corovic, 2013). When empirically compared, previous research deemed bivariate associations to be the more appropriate analysis to conduct, as bivariate associations were found to be significantly more predictive of offender characteristics than thematic and typological approaches (Goodwill, Alison \& Beech, 2009).

\section{Previous research}


There is a dearth of international research that has examined the bivariate relationships between crime scene behaviors and offender past offences. Davies, Wittebrood and Jackson (1997) were among the first to investigate whether offence behaviors are predictive of criminal history. The authors requested data from 43 British Police forces, resulting in data from 33 forces making this a much larger and more representative sample than that which had been previously analyzed. In total, a sample of 210 UK stranger rapists were considered, using logistic regression to consider whether particular offence behaviors could predict the offenders' preconvictions. Offence behaviors were categorized into the following behavioral themes: concealing identity, ensuring personal safety, familiarity with the justice system, criminal behavior, controlling the victim, method of approach and alcohol. Offender pre-conviction variables were: custodial sentence, criminal record, burglary, drug related offences, robbery, sexual offence, theft, violence and having committed a 'one-off' sexual offence.

The study was successful in linking specific offence behaviors to offender pre-convictions. The authors produced models which could be used by offender profilers and Behavioral Investigative Advisors to predict the likelihood that an unknown offender had a particular criminal conviction if their crime scene behavior was known. Some of their key findings showed that offenders who took fingerprint precautions were four times more likely to have convictions for burglary and semen destruction indicated that offenders were four times more likely to have had a sexual offence conviction. Reference to the police indicated that the offender was over five times more likely to have a criminal record and twice as likely to have a conviction for violence. Following on from this, a number of studies looked to replicate the findings of Davies et al. (1997) in various ways using similar crime scene behavioral factors. 
In the Netherlands, Jackson, Van Den Eshof and De Kleuver (1997) revealed some similar findings. They concluded that offenders who forced entry were more likely to have convictions for burglary and violent offenders were more likely to have pre-convictions for violence. However, the researchers found little difference in the antecedent patterns of rapists and burglars and concluded that investigating the relationship between offence behavior and criminal history of rapists would be of little use to offender profiling. Similarly, in New Zealand, Scott et al. (2006) found partial support for the previous studies. Forced entry was found to be indicative of both theft and violence pre-convictions. Offenders who stole from the victim were more likely to have robbery and theft pre-convictions. No significant associations were found for offenders who took fingerprint precautions and offenders who were more violent. However, the use of correlational analysis within the study limits the predictive utility of the findings.

Adding to previous research findings, Ter Beek et al. (2010) found that offenders who stole from the victim were more likely to have previous convictions for property crime and pre convictions for violence. In addition, offenders who forced the victim to disrobe herself were more likely to have prior sexual offence. Lea, Hunt and Shaw (2010), despite the main study focusing on the sexual assault of older females, made some attempt to explore associations between offender behavior and criminal history. With a sample of 106 UK stranger rapists, they found that offenders who stole from the victim were more likely to have pre-convictions for theft, supporting previous research findings. They also found that offenders who took disguise precautions were more likely to have a criminal record, whilst no significant association between violent offence behaviors and violent pre-convictions were found. Consequently, the above studies indicate that there is some evidence that 
offence behaviors may be useful in predicting the criminal history of stranger rapists, which may subsequently assist with potential nominal prioritization and identification.

\section{Evolution of sexual offending over time}

When examining the applicability of findings from 1990s, it is important to highlight how sexual offenders and offending behaviors may have changed. A recent report by the National Crime Agency (NCA) (2016) has highlighted the significant changes in the way people communicate and socialize, with one in three relationships now starting online. With this change in our communication style, this is also likely to be reflected in how offenders operate (Almond. McManus, Chatterton, 2017). The NCA (2016) also report that there has been a six-fold increase in the number of internet facilitated rapes between 2009-2014, with the report concluding that a 'new type of sexual offender' (p.3) exists, that quickens the pace of dating online using grooming strategies (Krasnova, Spiekermann, Koroleva \& Hildebrand, 2010; Sheehan \& Sullivan, 2010).

Additionally, related to the findings above, the offender-victim relationship is more difficult to identify, categorize and operationalize. How the term 'stranger' is currently defined can be very problematic, given the changes in how relationships develop from stranger to known. Williams et al. (2016) highlight the issue within their study of crossover from stranger to known child sexual offenders with this most problematic within extra-familial categories, as these can include a range of known victims (indirect communication, for example via email) to complete strangers, or studies with no real definition given. Currently the guidance for 'strangers' as documented within the Serious Crime Analysis Section (SCAS) (2011) within their codes of practice, does not give any further information than "where the relationship 
between the offender and victim is stranger or unknown" (p.6). The NCA definition for a stranger is "Where the victim and offender have had no or limited previous legitimate contact (physical, verbal or electronic) prior to the offence" (Personal communication, 2017). A recent article reviewed societal and police issues with the term 'stranger', which indicated that individuals have changed their interpretation of a 'stranger' due to online interactions (McManus \& Almond, 2017). Online interactions allow individuals to transfer interactions from stranger status, to non-stranger much quicker than if this were to occur offline, leading victims to put themselves in dangerous situations, such as meeting in an offenders' home (McManus \& Almond, 2017).

Other potential effects on the evolution of sexual offending should also consider legal and investigative changes that have occurred since 1990s. Various new legislation has been introduced over the years to assist in dealing with sexual offending; for example, the Sexual Offending Act (2003) outlines offences dealing with exploitation of children through indecent images of children, key child contact offences including rapes, non-consensual penetration, and other sexual offences (see McManus \& Almond, 2014 for more information). With this in mind, there has been reported increases in the number of sexual offences committed on children (McManus \& Almond, 2014) and adults (ONS, 2016; 2017), which has likely increased responses to sexual offending. ONS (2017) highlights that figures for sexual offences for year ending June 2017 as the highest figure recorded by police since 2002, with their explanation for this peak being improved recording practices and increases in victim self-disclosure. In support of this, specialized sexual offending units exist in all police forces within the UK, therefore, any changes in crime scene behaviors displayed and criminal histories may be a reflection of the 
specialist investigators collection of evidence and recording of relevant information. All of the above factors should be considered when exploring current stranger rapists, and the potential interaction between them.

\section{The current study}

Currently, the Davies et al. (1997) study is the only UK study to fully examine direct, bivariate associations between offender behaviors and criminal history of convicted male stranger rapist on a female victim, and is, therefore, often referred to by UK BIAs. However, crime trends and offending behaviors are continually evolving and changing (ONS, 2016; 2017; NCA, 2016). Thus, it is vital that research is updated using contemporary data samples in order to effectively inform investigative practice of reliable offence behaviors (Milton, 2013). Furthermore, some of the methods of analysis employed by Davies et al. (1997) is now considered inappropriate. Davies et al. used .1 as their indication of significance, whilst the cut-off figure used in research is .05 as a maximum. Davies et al. also used a stepwise regression, with research now concluding that this procedure is prone to over-fitting data and the resulting model may also be influenced by random variations (Field, 2013). The alternative enter regression procedure, in which all variables are simultaneously entered into the model, is considered to be more appropriate than the stepwise procedure (Field, 2013). The limitations outlined above with the Davies et al. (1997) study, highlights an urgent need to replicate the study with a revised methodology and contemporary dataset, particularly given that the findings of this study are still utilized to assist with investigations of stranger rapes.

The overall aim of the study was to explore and compare the validity of the crime scene behaviors utilized within the Davies et al. (1997) in predicting the 
criminal record of a stranger rapist. In addition, the study sought to explore whether other behaviors, not included within the Davies et al. study, may hold greater predictive ability in regards to an offenders' criminal history.

\section{Method}

\section{Sample}

The data sample consisted of 474 convicted male stranger rapists against a female victim, which were obtained from the Serious Crime Analysis Section (SCAS) UK database. SCAS was developed following the review of the Yorkshire Ripper Enquiry, which highlighted the need for a national database to hold details of serious sexual offences committed in the UK. This dataset, which includes sexually motivated or motiveless murders, is the only of its type in the UK. SCAS works to identify the potential emergence of serial killers and serial rapists at the earliest stage of their offending.

For the purpose of the study, the term 'stranger rape' was defined as a rape where the perpetrator and victim were unknown to each other. As mentioned previously, this is the definition widely used by police forces following the codes of practice documentation (Serious Crime Analysis Section, 2011). The recorded offences occurred between 2003 and 2015 and were selected based on whether the victim was female and aged over 16 . All cases involved one offender and one victim, to ensure that the analysis was not biased by certain serial offenders (Canter, Bennell, Alison \& Reddy, 2003). Furthermore, the sample only contained offenders who were UK nationals, as the conviction histories of non-UK citizens were not available. 
Regarding the demographic information of the sample, the average age of the convicted male offender was 28.72 years $(S D=10.03)$ and $73.4 \%$ of the sample were of European descent, $16.5 \%$ were of African Caribbean descent, $8 \%$ were Asian, $1.6 \%$ were classified as other and $1.1 \%$ were classified as unknown.

\section{Procedure}

Data were extracted from the SCAS database. Variables were dichotomous: 1 indicating the presence of behavior, or conviction and 0 indicating absence. It has been found that employing a dichotomous approach to data not originally intended for research purposes assures more reliability and clarity (Almond, McManus, Giles \& Houston, 2015).

Crime scene behavior consisted of 22 variables in total (see Table 1). These variables can be broadly categorized into the following themes: concealing identity, criminal behavior, departure precautions taken, approach, location, clothing and scene.

The original variables identified by Davies et al. (1997) were selected for analysis and also expanded upon in order to further the potential investigative utility of findings. Due to difficulty in verifying whether the offender was drunk during the offence and whether the offender intentionally lied to mislead the victim, these variables which were examined by Davies et al. (1997) were excluded from this study.

Pre-convictions consisted of nine variables: Criminal record, Burglary, Criminal damages, Drugs, Robbery, One off sexual offence ${ }^{1}$, Sexual offence, Theft and Violence (See Table 2). The original variables identified by Davies et al. (1997)

\footnotetext{
${ }^{1}$ Apparently only ever committed one sexual offence (Davies et al., 1997).
} 
were selected for analysis and also expanded upon in order to further the potential investigative utility of findings. One pre-conviction variable (custodial sentence i.e. prison sentence) analyzed in the Davies et al. (1997) study was excluded as there were issues regarding the accuracy of the data, as it was unclear from the database whether the offender was imprisoned before, as a result of, or subsequent to the offence.

Inter-rate reliability analysis is conducted within SCAS with clean, anonymized, pre-coded data given to the researchers. SCAS have a rigorous method to ensure the input of data are accurate. SCAS staff undergo several months training, with a 'Quality Control Guide' utilized by everyone inputting data on the database. Where unusual activity/information is encountered, a dedicated, experienced team meets to review the information and make a decision. Within SCAS, each case also undergoes a detailed quality assurance process prior to any analysis taking place. This involves a review of the inputted information in comparison to case details, by an analyst from within the team. Any anomalies or errors are fed back to the inputter and amended on the database (SCAS, personal communication, 2017).

\section{Statistical Analysis}

The aim of this study was to predict dichotomous conviction variables based on offence behavior. Therefore, data analysis occurred in two stages. In stage one, chisquare analyses were used to examine whether there were any significant associations between the offence behavior variables and the pre-conviction variables. The odds ratios of any significant associations were also calculated, in order to indicate the statistical probability of an offender having a certain type of pre- 
conviction based on offence behavior (Goodwill et al., 2011). As proposed by Chen, Cohen and Chen (2010), odds ratios were considered to signify small $(<1.5)$, medium (1.5-5) or large effect $(>5)$ sizes.

For stage two, any significant offence behavior variables identified by the chisquare analyses were then entered into a logistic regression analysis, in order to ensure offence variables produced the optimal predictive model for conviction variables (Chan, 2012). Logistic regression models assess the predictive ability of a set of independent variables on a categorical dependent variable. The contribution of each predictor variable within the model is indicated; statistically significant tests indicate that the variable contributes to the predictive accuracy of the outcome variable. The assumptions of logistic regression were assessed prior to analysis, and all were met. A forced entry, binary logistic regression was conducted.

\section{Results}

\section{Descriptive statistics}

Table 1 shows the presence of crime scene behaviors in the Davies et al. study and within the current study. As can be seen, there were a number of variables included within the current study that were not utilized within the Davies et al. study. Therefore, comparisons of their current applicability were not possible. However, for the 10 variables that were collected within both studies, there were significant differences in their presence across six, indicating significant changes in the nature 
of these variables across the two studies. Sighting precaution, for example wearing a mask was seen to be significantly more applicable for stranger rapists within the Davies et al. study compared to the current study, occurring in 15 times more cases. This pattern of Davies et al. recording a significantly higher presence of the behavior compared to the current study was seen in the variables: Safe departure, Forced entry, Fingerprint precaution, Violence, and Theft. The only comparison variable that was higher within the current study compared to the Davies et al. study was Confidence approach (51.1\% compared to 48\%), although this difference was not significant.

Insert Table 1 here: Comparison of variables across Davies et al. (1997) and the current study

Similarly, Table 2 explores the differences between Davies et al. (1997) and the current study regarding the presence of pre-conviction variables. Results showed that across all comparable variables there were significant differences between the two studies. For the pre-convictions of Theft, Burglary, Violence, Sexual offence, Robbery and general Criminal record, the Davies et al. (1997) study recorded a significantly higher number. In contrast, there were a significantly higher presence of One-off sex offence and Drug pre-convictions within the current sample, compared to the Davies et al. (1997) study.

Insert Table 2 here: Comparing the presence of pre-conviction variables within Davies et al. (1997) and the current study.

\section{Exploring stranger rapists behaviors and conviction history}


Chi-square analyses were conducted to explore significant associations between individual behaviors and previous conviction types. Table 3 summarizes the results showing the odds ratios between the stranger rape crime scene behaviors and previous criminal histories. It should be noted that the previous offence of One-off sexual offence and any previous Sexual offences were not included as no associations were found for any of the behaviors. In addition, the crime scene behaviors of: Daylight, Inside, Outside, Public, Private, Violence, Gagging, Surprise/Blitz, Offender disrobes victim, Victim disrobes self, were not included in as there were no associations found with any of the previous criminal histories.

Insert Table 3 here: Table 3. Odds ratios showing the relationship between offender criminal histories and offence behaviors of stranger rapists

\section{Reference to the police}

Offenders who made reference to the police when speaking to the victim were three times more likely to have a previous conviction for Burglary, $\chi^{2}(1)=14.185, p<.001$, and over twice as likely to have convictions for Criminal damage, $\chi^{2}(1)=10.290, p=$ $.001, \operatorname{Drugs}\left(\chi^{2}(1)=6.437 p<.05\right.$, and/or Theft, $\chi^{2}(1)=6.963, p<.01$.

\section{Forced entry}

If a stranger rapist exhibited the behavior Forced entry, then he was approximately three times more likely to have a Criminal record, $\chi^{2}(1)=4.218, p<.05$. In addition, he was three and a half times more likely to have convictions for Theft, $\chi^{2}(1)=$ 11.182, $p=.001$, and two and half times more likely to have Burglary, $\chi^{2}(1)=9.138$, $p<.01$, and/or Robbery convictions, $\chi^{2}(1)=5.519, p<.05$. 


\section{Theft from victim}

A stranger rapist who stole from his victim was found to be nearly twice as likely to have a prior Criminal record, $\chi^{2}(1)=6.789, p<.01$, and one and half times more likely to have Robbery, $\chi^{2}(1)=4.283, p<.05$, and/or Theft convictions, $\chi^{2}(1)=$ $3.972, p<.05)$

\section{Victim's phone disabled}

Offenders who disabled their victim's phone were nearly five times as likely to have a pre-conviction for Violence, $\chi^{2}(1)=7.178, p<.01$, and just under four times as likely with regards to Burglary pre-convictions, $\chi^{2}(1)=4.981, p<.05$.

\section{Blindfolding}

If a stranger rapist blindfolded his victim then they were around two and a half times more likely to have previous convictions of Burglary, $\chi^{2}(1)=8.185, p<.01$, and/or Drugs, $\chi^{2}(1)=5.099, p<.05$.

\section{Weapon use}

The use of weapon by a stranger rapist was found to increase the likelihood of a Robbery, $\chi^{2}(1)=4.682, p<.05$, and Theft pre-conviction, $\chi^{2}(1)=4.724, p<.05$, by approximately one and a half.

\section{Precautionary behaviors}

The use of behavior Sighting precautions, for example by wearing a mask, held the highest odds ratio across all comparisons, thus indicating a presence of this behavior was over six times as likely to have a previous conviction for Criminal damage, $\chi^{2}(1)$ $=9.366, p<.01$. Fingerprint precautions was around three times more likely to be used by stranger rapists who had previous convictions for Drugs, $\chi^{2}(1)=5.532, p<$ 
.05 , with Semen destruction just over two times as likely to have convictions for Robbery, $\chi^{2}(1)=4.581, p<.05$.

\section{Time of day and approach method}

The use of behaviors Darkness, $\chi^{2}(1)=5.519, p<.05$, and Confidence approach, $\chi^{2}$ $(1)=4.313, p<.05$, were both associated in the opposite direction, thus indicating the stranger rapist was not likely to have a previous conviction for Criminal damage.

\section{Logistic regressions models}

The next section takes those significant behavior associations found above and entered them into binary logistic regressions using the specific offence types (see Table 4).

\section{Criminal record}

Two behaviors were found to increase the likelihood of a Criminal record of a stranger rapist were Theft from victim and Forced entry (due to violations of normality, Victims phone was disabled was not included). A binary logistic regression analysis was conducted to predict presence of Criminal record using Theft from victim and Forced entry as predictors with the resulting model statistically significant, $\chi^{2}(2, N=474)=10.515, p<.01$. The Wald criterion indicated that only the behavior Theft from the victim made a significant contribution to prediction $(p=.025)$. The model as a whole explained between 3.1\% (Cox \& Snell $\mathrm{R}^{2}$ ) and 4.6\% (Nagelkerke $\mathrm{R}^{2}$ ) of the variance in Criminal record status, and correctly classified $73.2 \%$ of cases when both behaviors were present.

\section{Burglary}


When the four significant stranger rapist behaviors (see Table 4) were entered into a binary logistic regression, with the resulting model significant, $\chi^{2}(4)=25.062, p<$. 000). The Wald criterion indicated that only the behavior Forced entry $(p=.040)$ and Reference to the police $(p=.002)$ made a significant contribution to the prediction of Burglary pre-conviction. The model explained between 5.1\% (Cox \& Snell $\mathrm{R}^{2}$ ) and $7.2 \%$ (Nagelkerke $\mathrm{R}^{2}$ ) of the variance of Burglary status, and correctly classified $67.5 \%$ of cases.

\section{Criminal damage}

Within the chi-square analysis, five behaviors were found to be significantly associated with a pre-conviction of Criminal damage. A logistic regression was performed to ascertain the effect of these five behaviors (see Table 4) on preconviction for Criminal damages. The full model containing all predictors was statistically significant, $\chi^{2}(5)=25.093, p<.000$ ) indicating that the model was able to distinguish between offenders who had Criminal damage offences and those who did not. However, only Sighting precautions $(p=.04)$, Reference to the police $(p=.01)$ and Darkness $(p=.04)$ made a statistically significant contribution to the model. The model as a whole explained between 5.2\% (Cox \& Snell R²) and 7.1\% (Nagelkerke $\mathrm{R}^{2}$ ) of the variance of Criminal damages and correctly classified $66.2 \%$ of cases.

\section{Drugs}

Three stranger rapist behaviors were found to be associated with a previous history of Drugs: Reference to the police; Finger print precautions and Blindfold (Table 4). When the three significant offender behaviors were entered into a binary logistic, the resulting model was significant, $\chi^{2}(3)=12.528, p<.01$. However, only Reference to the police ( $p=.03$ ) made a statistically significant contribution to the model. The 
model as a whole explained between 3\% (Cox \& Snell R2) and 4\% (Nagelkerke R²) of the variance of Drugs and correctly classified $78.5 \%$ of cases when all three variables were included.

\section{Robbery}

Chi-square analyses between offenders with previous convictions for Robbery ( $n=$ 73) and offenders without previous convictions for Robbery $(n=401)$ identified four significant associations- Semen destruction, Theft from the victim, Forced entry and Weapon (Table 4). A binary logistic regression was found to be statistically significant, $\chi^{2}(4)=12.879, p<.05$, however, only Forced entry was found to be a marginally non-significant predictor $(p=.05)$. The model explained between $2.7 \%$ $\left(\right.$ Cox \& Snell $\mathrm{R}^{2}$ ) and $4.6 \%$ (Nagelkerke $\mathrm{R}^{2}$ ) of the variance of Robbery and correctly classified $84.6 \%$ of cases when all four variables were included.

\section{Theft}

Chi-square analyses between offenders with previous convictions for Theft $(n=218)$ and offenders without convictions for theft $(n=256)$ identified four significant associations - Theft from victim, Forced entry, Reference to the police and Weapon (Table 4). When the four significant offender behaviors were entered into a binary logistic regression the resulting model was significant, $\chi^{2}(4)=20.450, p<.000$. Two behaviors were found to significantly contribute to the model: Forced entry $(p=.007)$ and Reference to the police $(p=.035)$. The resulting model explained between $4.2 \%$ (Cox \& Snell $\mathrm{R}^{2}$ ) and 5.6\% (Nagelkereke $\mathrm{R}^{2}$ ) of the variance of pre-conviction for Theft, and correctly classified $61 \%$ of cases.

\section{Violence}


Chi-square analysis between offenders with a previous conviction for Violence $(n=$ 132) and offenders without a previous conviction for violence $(n=342)$ identified one significant association- Victim's phone being disabled. A binary logistic regression was statistically significant, $\chi^{2}(1)=6.256, p<.05$ ), with this this behavior predictive of pre-conviction for Violence $(p=.014)$. The model was able to distinguish between offenders who had a criminal record for Violence and those who did not. The model as a whole explained between 1.3\% (Cox \& Snell $\mathrm{R}^{2}$ ) and 1.9\% (Nagelkerke $\mathrm{R}^{2}$ ) of the variance in Violence status, and correctly classified $72.8 \%$ of cases.

Insert Table 4 here: Table 4. Logistic regression result for offence behaviors which differentiate offenders with and without criminal records

\section{Discussion}

The overall aim of the study was to explore and compare the validity of the crime scene behaviors utilized within the Davies et al. (1997) study in predicting the criminal record of a stranger rapist, using a more contemporary sample with a more appropriate stringent test of significance. In addition, the study sought to explore whether other crime scene behaviors, not included within the Davies et al. study, may hold greater predictive ability in regards to an offenders' criminal history. Twenty-two offence behavior variables were explored in relation to their individual predictive validity for seven pre-conviction types. The results revealed several significant findings.

A key finding of the current study was that out of the 10 comparable factors with the Davies et al. (1997) study, six of these significantly differed. All of these six factors recorded a significantly higher presence in the Davies et al. study, than the current study. There are a number of potential explanations for this. First, sexual 
offending legislation has been significantly amended through the implementation of the Sexual Offences Act (2003), for example, offences such as digital penetration are now classified as rape. The investigation and recording of sexual investigations have changed, with recording practices improving through regular inspections of police forces (HMIC) and reporting of data through the ONS. In addition, the changing nature of sexual offending over the last 20 years may reflect the differences between the two studies. For example, Sighting precautions were 15 times more likely to appear within the Davies et al. study than the current study. Similarly, when comparing the presence of pre-conviction variables across the two studies, there was a significant difference for all offence types, except Criminal damage. The pre-conviction offences of Burglary, Violence, Sexual offence, Theft and Robbery were found to be significantly higher within the Davies et al. (1997) study, with only One-off sex offence and Drugs found to be significantly higher in the current study.

Additionally, when comparing the results of two studies it is important to identify differences within the methodology. Some issues were identified within the Davies et al. study, which indicated that the term 'stranger' was not clearly defined within the study, with no mention of how the variables were collected or coded. The data collection span within the Davies et al. study also highlights issues in the potential accuracy of the criminal history, with previous histories collected from 1965. In addition, with one force only sending 10 cases across a 28-year period, this may indicate that prolific offenders were the focus of the data collection, which may explain the higher rates of criminal histories. Consequently, the factors extracted from the Davies et al. study should be reviewed alongside the findings of the current 
study, as not only have the pre-conviction histories of convicted rapists altered, but so have the behaviors exhibited by offenders committing stranger rapes.

The current sample of individual stranger rapist behaviors was then explored to identify the key pre-conviction types that were significantly associated with the behavior. Key findings indicated that instrumental behaviors, showing criminal experience, was indicative of more instrumental type criminal histories (e.g., property), with only a few factors associated with violence pre-convictions and non with sexual pre-convictions. Reference to the police and Forced entry were both significantly associated with prior history of Burglary and Theft; however, Reference to the police was also seen to be associated with Criminal damage and Drugs, whereas Forced entry was linked to Robbery and Criminal Record generally. The prior convictions linked to Forced entry indicate a trend towards acquisitive crime types, with previous research finding Forced entry to be predictive crime scene behavior across these offence types (Davies et al., 1997; Jackson et al., 1997; Scott et al., 2006). This suggests that Forced entry may be a key indicator of acquisitive type previous offences, with the combination of other crime scene behaviors informing the specific type of acquisitive offence. The behavior of Theft from victim was significantly associated with three criminal conviction histories: Robbery, Theft and Criminal record, again indicating an acquisitive offending history to those stranger rapists who display this behavior at the scene. One of the strongest associations was found when exploring the behavior Sighting precaution, this was found to be used over six times more by offenders with prior Criminal damage convictions. Previous research has not investigated the relationship between Criminal damage and offence behaviors within stranger rapists. The fact that a preconviction for Criminal damage included the most offence behaviors is encouraging, 
and suggests that future research should consider further exploring this conviction variable.

No behaviors were found to be associated with Sexual offence preconvictions. This contradicts previous research findings, which concluded that Semen destruction, Sighting precautions and the Victim disrobing themselves were indicative of the offender having a Sexual offence pre-conviction (Davies et al., 1997; Ter Beek et al., 2011). However, when referring to Table 2, this indicates that this may be due to the changing nature in sexual offending rates (Office for National Statistics, 2016; 2017) with the number of offenders with previous convictions for sexual offences having nearly halved since the Davies et al. (1997) study. Similarly, a new finding for the current study shows that the behavior Disabling a victim's phone was only associated with the pre-convictions of Burglary and Violence. This may reflect the increasing use of mobile phones (and general internet facilitated technology) in recent times (Almond et al., 2017; National Crime Agency, 2016) and may be used as a method to stop a victim calling for help. However, it should be noted that this behavior would not have been available in previous studies such as Davies et al. (1997).

Within the current study, many of the findings revealed are new and not previously captured, or measured. This has been attributed to the fact that offending behaviors amongst the sex offender population is changing (National Crime Agency, 2016). This change may be facilitated by the growth of the internet and the general increase in online activity for day to day activities and criminal activities (Almond et al., 2017). For instance, recent years have seen a rise in the phenomenon of online dating initiated stranger rape resulting in a new type of sex offender (National Crime Agency, 2016). Analysis of online dating stranger rapists conducted by the NCA's 
SCAS has revealed marked differences in comparison to other stranger rapists (National Crime Agency, 2016). For example, online dating offenders are less likely to have criminal convictions (49\%) in comparison to other stranger rapists (84\%). In addition, those online dating offenders with criminal convictions are for lesser offences, such as traffic offences (National Crime Agency, 2016). Futhermore, forensic capabilities and specialized investigative agencies are now in place with increased identification methods to detect and detain those engaging in such behaviors (McManus \& Almond, 2014). In light of this rising problem, it is suggested that future research further explores the potential impact of this new type of sexual offender, in order to better inform investigative practice of the behaviors and dynamics of this type of sexual offender.

\section{Limitations}

Whilst the study obtained a relatively large sample size, several limitations must be considered. Firstly, the data only contained detected cases. It is well accepted that rape is an underreported crime (Office for National Statistics, 2016). Although data were provided by SCAS - a national database - and therefore can be considered as a representative sample of UK sexual offences, this still may be only a fraction of committed crimes. Therefore, it is possible that the crime scene behaviors of undetected offenders differ from those of detected offenders. In addition this study used convictions; other measure such as arrest history might be more representative.

Furthermore, the data were obtained for investigative purposes and not research purposes. Inaccurate reporting from police officers and victim statements may lead to biases and missing information, which is not ideal for empirical research 
(Milton, 2013). Whilst this study employed a dichotomous approach to the data, which assures greater reliability, it can also be argued that using data collected for investigative purposes reinforces the ecological validity of the results (Mokros \& Alison, 2002).

\section{Conclusion}

The aim of this study was to establish whether it is possible to make inferences of past offences of a stranger rapist based on crime scene offence behaviors. The study sought to update seminal research conducted by Davies et al. (1997) using a contemporary sample. The key finding of this study is that stranger rapists significantly differed in their pre-conviction histories and their offence behaviors when compared to the findings within the Davies et al. (1997) study. There are various potential reasons for the differences between the two studies, with this possibly reflecting changes in sexual offenders and the modus operandi of sexual offending generally (National Crime Agency, 2016), with other explanations highlighting increases in sexual offending rates and victim self-disclosure (Office for National Statistics, 2016 \& 2017), changes in legislation, and police responses to sexual offences (McManus \& Almond, 2014), with the interaction between all factors also to be considered.

In addition, the finding that some offence behaviors were predictive of the preconvictions of a stranger rapist has a number of important implications. First, being able to determine that offence behaviors are predictive of criminal history, but also specific behaviors that can assist in prioritizing potential nominals is a great asset to sexual offence investigations. This could improve the detection and apprehension rates of sexual offenders, but could also significantly reduce both time and financial 
costs, resulting in investigative resources being employed more efficiently (Deslauriers-Varin \& Beauregard, 2013; Bennell, Jones \& Melnyk, 2009). The current findings are of use to BIAs, who are reliant on statistical information to support any behavioral claims made (Rainbow \& Gregory, 2011). As the findings of the current paper have identified different behaviors and convictions, it is important that changes occur in the current use of Davies et al. (1997) and that continuous reviews are conducted to update the working model.

Future research should seek to encourage the collection of key crime scene behaviors and pre-conviction histories to ensure the resulting model reflects the current methods employed by stranger rapists. Importantly, the current research brings into question the use of the term 'stranger' and how this is being identified and categorized within UK policing. The increases within internet facilitated rapes (Almond et al. 2017; National Crime Agency, 2016) highlights that the line between known and stranger is becoming more blurred as individuals use various communication methods to groom stranger victims to meet (McManus \& Almond, 2017). Thus, the method of identification of victims (for example, by an initial online interaction, a brief encounter in public, or no previous interaction) by stranger rapists should be recorded and explored in future research to further understand the term 'stranger'.

\section{References}

Alison, L. Goodwill, A., \& Alison, E. (2015) Guidelines for profilers. In L. Alison (Eds.) The Forensic Psychologist's Casebook: Psychological Profiling and Criminal Investigation. Willan Publishing: Devon. 
Alison, L., Goodwill, A., Almond, L., van den Heuvel, C., \& Winter, J. (2010) Pragmatic Solutions to Offender Profiling and Behaviorallnvestigative Advice. Legal and Criminological Psychology, 15, 115-132.

Almond, L., McManus, M. A., Giles, S., \& Houston, E. (2015). Female Sex Offenders: An Analysis of Crime Scene Behaviours, Journal of Interpersonal Violence, 1-22.

Almond, L.A., \& McManus, M.A., \& Chatterton, H. (2017). Internet Facilitated Rape: A Multivariate Model of Offence Behavior. Journal of Interpersonal Violence. DOI: https://doi.org/10.1177/0886260517718187

Bennell, C., Jones, N. J., \& Melnyk, T. (2009). Addressing Problems with Traditional Crime Linking Methods using Receiver Operating Characteristic Analysis, Legal and Criminological Psychology, 14, 2930310.

Canter, D., Bennell, C., Alison, L., \& Reddy, S. (2003). Differentiating sex offences: A behaviourally based thematic classification of stranger rapes. Behavioral Sciences \& the Law, 21, 157-174.

Chan, K. L. (2012). Predicting the risk of intimate partner violence: The Chinese risk assessment tool for victims. Journal of Family Violence, 27, 157-164.

Chen, H., Cohen, P., \& Chen, S. (2010). How Big is a Big Odds Ratio? Interpreting the Magnitudes of Odds Ratios in Epidemiological Studies, Communications in Statistics - Simulation and Computation, 39, 860-864.

Corovic, J. (2013). Offender Profiling in Cases of Swedish Stranger Rape (Published Doctoral Dissertation), Stockholm University: Stockholm, Sweden. 
Corovic, J., Christianson, S. A., \& Bergman, L. R. (2012). From Crime Scene Actions to Stranger Rape to Prediction of Rapist Type: Single- Victim or Serial Rapist? BehavioralSciences and the Law, 30, 764-781

Davies, A., Witterbrood, K., \& Jackson, J. L. (1997). Predicting the Criminal Antecedents of a Stranger Rapist from his offence Behavior. Science \& Justice, 37(3), 161-170.

Deslauriers-Varin, N., \& Beauregard, E. (2013). Investigating Offending Consistency of Geographic and Environmental Factors Among Serial Sex Offenders: A Comparison of Multiple Analytical Strategy, Criminal Justice and Behavior, 40(2), 156-179.

Dowden, C., Bennell, C., \& Bloomfield, S. (2007). Advances in offender profiling: A systematic review of the profiling literature published over the past three decades. Journal of Police and Criminal Psychology, 22, 44-56.

Field, A. P. (2013). Discovering Statistics using IBM SPSS Statistics (4 ${ }^{\text {th }}$ ed.) London: Sage.

Goodwill, A. M., Alison, L. J., \& Beech, A. R. (2009). What works in Offender Profiling? A Comparison of Typological, Thematic, and Multivariate Models, Behavioral Sciences and the Law, 27, 507-529.

Hakkanen, H., Lindlof, P., \& Santtila, P. (2004). Crime Scene Actions and Offender Characteristics in a Sample of Finnish Stranger Rapes. Journal of Investigative Psychology and Offender Profiling, 1, 17-32. 
Her Majesty's Constabulary (2014). Crime recording: Making the victim count. Retrieved from https://www.justiceinspectorates.gov.uk/hmicfrs/wpcontent/uploads/crime-recording-making-the-victim-count.pdf

Jackson, J.L., van den Eshof, P., \& de Kleuver, E.E. (1997). A research approach to offender profiling. In J. L. Jackson \& D. A. Bekerian (Eds.), Offender profiling: Theory, research, and practice, Chichester, England: Wiley.

Krasnova, H., Spiekermann, S., Koroleva, K., \& Hildebrand, T. (2010). Online social networks: why we disclose. Journal of Information Technology, 25(2), 109125.

Lea, S. J., Hunt, L., \& Shaw, S. (2011). Sexual Assault of Older Women by Strangers, Journal of Interpersonal Violence, 26(11), 2303-2320.

Lundrigan, S., \& Mueller-Johnson, K. (2013). Male Stranger Rape: A BehavioralModel of Victim-Offender Interaction, Criminal Justice and Behavior, 40(7), 763-783.

McManus, M.A., \& Almond, L. (2014). Trends of indecent images of children and child sexual offences between 2005/2006 and 2012/2013 within the United Kingdom. Journal of Sexual Aggression, 20(2), 142-155.

McManus, M.A., \& Almond, L. (2017, July 28). Stranger danger in the online and real world. The Conversation. Retrieved from:

https://theconversation.com/stranger-danger-in-the-online-and-real-word$\underline{79517}$

Ministry of Justice (2013). An Overview of Sexual Offending in England and Wales. Ministry of Justice, Home Office \& the Office for National Statistics. Statistics 
bulletin. Retrieved from: https://www.gov.uk/government/statistics/anoverview-of-sexual-offending-in-england-and-wales

Milton, E. (2013). Testing Case Linkage and Offender Profiling Using Temporal Proximity and Inter-Crime Distance Against BehavioralVariables (Unpublished Thesis Dissertation), University of Liverpool: Liverpool, UK.

Mokros, A., \& Alison, L. J. (2002). Is Offender Profiling Possible? Testing the Predicted Homology of Crime Scene Actions and Background Characteristics in a Sample of Rapists, Legal and Criminological Psychology, 7(1), 25-43.

National Crime Agency. (2016). Emerging new threat in online dating: Initial trends in internet dating-initiated serious sexual assaults. London: National Crime Agency. Retrieved from:

http://www.nationalcrimeagency.gov.uk/publications/670-emerging-newthreat-in-online-dating-initial-trends-in-internet-dating-initiated-serious-sexualassaults/file

Newman, F. (2011). A Geo-BehavioralModel of Stranger Rape: Implications for Offender Profiling and Linking (Unpublished Doctoral Dissertation), University of Liverpool: Liverpool, UK.

Office for National Statistics (2015). Violent crime and sexual offences - Intimiate personal violence and serious sexual assault. Retrieved from: https://www.ons.gov.uk/peoplepopulationandcommunity/crimeandjustice/com pendium/focusonviolentcrimeandsexualoffences/2015-0212/chapter4violentcrimeandsexualoffencesintimatepersonalviolenceandseriou ssexualassault\#reporting-of-serious-sexual-assault 
Office for National Statistics (2016). Overview of violent and sexual offences.

Retrieved from:

https://www.ons.gov.uk/peoplepopulationandcommunity/crimeandjustice/com pendium/focusonviolentcrimeandsexualoffences/yearendingmarch2015/chapt $\underline{\text { er1overviewofviolentcrimeandsexualoffences\#main-points }}$

Office for National Statistics (2017). Crime in England and Wales: year ending June 2017 Retrieved from:

https://www.ons.gov.uk/peoplepopulationandcommunity/crimeandjustice/bullet ins/crimeinenglandandwales/june2017\#rise-in-police-recorded-sexualoffences

Petherick, W., \& Ferguson, C. (2013). BehavioralConsistency, the Homology Assumption and the Problems of Induction. In W. Petherick (ed). Profiling and Serial Crime: Theoretical and Practical Issues, $3^{\text {rd }}$ ed. Burlington: Elsevier Science.

Rainbow, L., \& Gregory, A. (2011). "What Behaviorallnvestigative Advisers Actually Do", in L. Alison and L. Rainbow (eds) Professionalizing Offender Profiling: Forensic and Investigative Psychology in Practice, Oxon: Routledge.

Scott, D., Lambie, I., Henwood, D., \& Lamb, R. (2006). Profiling Stranger Rapists: Linking Offence Behavior to Previous Criminal Histories Using a Regression Model.

Serious Crime Analysis Section. (2011). Codes of practice for use of the Serious Crime Analysis Section. Retrieved from: http:library.college.police.uk/docs/APPREF/SCAS-Codes-of-Practice-April2011.pdf 
Sexual Offences Act, c. 42 O.P.S.I. (2003).

Sheehan, V. \& Sullivan, J. (2010). A qualitative analysis of child sex offenders involved in the manufacture of indecent images of children. Journal of Sexual Aggression, 16(2), 143-167.

Ter Beek, M., Van Den Eshof. P., \& Mali, B. (2010). Statistical Modelling in the Investigation of Stranger Rape, Journal of Investigative Psychology and Offender Profiling, 7, 31-47.

Williams, M.W.H., Blackwood, K, Van Rensburg, J, Jones, D.T., Calvert, S.W. (2016). From known to stranger crossover: A retrospective study of child sex offenders released into custody. Sexual Offender Treatment, 11(1). 
Table 1. Comparison of variables across Davies et al. (1997) and the current study

\begin{tabular}{lcccc}
\hline Offence Behaviours & $\begin{array}{c}\text { Davies et al. } \\
\mathbf{n ~ ( \% )}\end{array}$ & $\begin{array}{c}\text { Current Study } \\
\mathbf{n}(\%)\end{array}$ & P value & $\begin{array}{c}\text { Odds } \\
\text { ratios }\end{array}$ \\
\hline Sighting Precaution & $59(28)$ & $12(2.5)$ & .0001 & 15.04 \\
Fingerprint Precaution & $32(15)$ & $18(3.8)$ & .0001 & 4.55 \\
Forced Entry & $53(25)$ & $34(7.2)$ & .0001 & 4.37 \\
Safe Departure & $67(32)$ & $51(10.8)$ & .0001 & 3.89 \\
Violence & $42(20)$ & $44(9.2)$ & .0002 & 2.44 \\
Theft & $84(40)$ & $152(32.1)$ & .0455 & 1.41 \\
Reference to Police & $27(13)$ & $43(9.1)$ & n.s & \\
Weapon & $63(30)$ & $115(24.3)$ & n.s & \\
Semen Destruction & $11(5)$ & $36(7.6)$ & n.s & \\
Confidence Approach & $101(48)$ & $242(51.1)$ & n.s & \\
Darkness & - & $388(81.9)$ & & \\
Offender Disrobes Victim & - & $338(71.3)$ & & \\
Public & - & $330(69.6)$ & & \\
Outside & - & $297(62.7)$ & & \\
Blitz orSurprise & - & $205(43.2)$ & & \\
Inside & - & $197(41.6)$ & & \\
Private & - & $187(39.5)$ & & \\
Victim Disrobes Self & - & $95(20.0)$ & & \\
Daylight & - & $94(19.0)$ & & \\
Blindfolding & - & $35(7.4)$ & & \\
Gagging & - & $13(2.7)$ & \\
Phone Disabled & - & $11(2.3)$ & & \\
\hline
\end{tabular}


Table 2. Comparing the presence of pre-conviction variables within Davies et al. (1997) and the current study.

\begin{tabular}{lcccc}
\hline Conviction Variables & $\begin{array}{c}\text { Davies et al } \\
\mathbf{n}(\%)\end{array}$ & $\begin{array}{c}\text { Current Study } \\
\mathbf{n}(\%)\end{array}$ & P value & $\begin{array}{c}\text { Odds } \\
\text { ratios }\end{array}$ \\
\hline Burglary & $118(56)$ & $154(32.5)$ & .0001 & 2.67 \\
Violence & $105(50)$ & $132(27.8)$ & .0001 & 2.59 \\
Sexual Offence & $67(32)$ & $78(16.5)$ & .0001 & 2.38 \\
Theft & $164(78)$ & $218(46)$ & .0001 & 2.24 \\
Criminal Record & $176(84)$ & $347(73.2)$ & .0024 & 1.89 \\
Robbery & $48(23)$ & $73(15.4)$ & .0224 & 1.63 \\
One-off sex offence & $143(68)$ & $396(83.5)$ & .0001 & 0.42 \\
Drugs & $21(10)$ & $104(22.0)$ & .0002 & 0.31 \\
Criminal Damages & - & $160(33.8)$ & & \\
\hline
\end{tabular}


Table 3. Odds ratios showing the relationship between offender criminal histories and offence behaviours of stranger rapists

\begin{tabular}{|c|c|c|c|c|c|c|c|}
\hline & $\begin{array}{l}\text { Criminal } \\
\text { Record }\end{array}$ & Burglary & $\begin{array}{l}\text { Criminal } \\
\text { Damage }\end{array}$ & Drugs & Robbery & Theft & Violence \\
\hline Fingerprint & & & & 3.0 & & & \\
\hline $\begin{array}{l}\text { Semen } \\
\text { Destruction }\end{array}$ & & & & & 2.29 & & \\
\hline $\begin{array}{l}\text { Sighting } \\
\text { Precaution }\end{array}$ & & & 6.18 & & & & \\
\hline Blindfolding & & 2.67 & & 2.26 & & & \\
\hline Safe Departure & & & 1.88 & & & & \\
\hline $\begin{array}{l}\text { Victim's Phone } \\
\text { Disabled }\end{array}$ & & 3.76 & & & & & 4.73 \\
\hline Theft & 1.86 & & & & 1.71 & 1.48 & \\
\hline Forced Entry & 2.91 & 2.86 & & & 2.49 & 3.56 & \\
\hline Confidence & & & 0.67 & & & & \\
\hline $\begin{array}{l}\text { Reference to } \\
\text { Police }\end{array}$ & & 3.25 & 2.74 & 2.31 & & 2.37 & \\
\hline Weapon & & & & & 1.80 & 1.59 & \\
\hline Darkness & & & 0.61 & & & & \\
\hline
\end{tabular}


Table 4. Logistic regression result for offence behaviours which differentiate offenders with and without criminal records

\begin{tabular}{|c|c|c|c|}
\hline $\begin{array}{l}\text { Offence Behaviour } \\
\text { Variables }\end{array}$ & $\begin{array}{c}\text { No Criminal } \\
\text { Record } n=127 \\
\%\end{array}$ & $\begin{array}{c}\text { Criminal } \\
\text { Record } n=347 \\
\% \\
\end{array}$ & Sig. \\
\hline Forced Entry & 3.1 & 8.6 & - \\
\hline \multirow[t]{2}{*}{ Theft } & 22.8 & 35.4 & 0.25 \\
\hline & $\begin{array}{c}\text { No Burglary } \\
\text { Conviction } n=320 \\
\%\end{array}$ & $\begin{array}{c}\text { Burglary } \\
\text { Conviction } n=154 \\
\%\end{array}$ & Sig. \\
\hline Victim's Phone Disabled & 1.3 & 4.5 & - \\
\hline Reference to Police & 5.6 & 16.2 & .002 \\
\hline Forced Entry & 4.7 & 12.3 & .040 \\
\hline \multirow[t]{2}{*}{ Blindfolding } & 5.0 & 12.3 & - \\
\hline & $\begin{array}{c}\text { No Criminal Damage Con- } \\
\text { viction } n=314 \\
\%\end{array}$ & $\begin{array}{c}\text { Criminal Damage } \\
\text { Conviction } n=160 \\
\% \\
\end{array}$ & Sig. \\
\hline Sighting Precaution & 1.0 & 5.6 & .04 \\
\hline Reference to Police & 6.1 & 15.0 & .01 \\
\hline Safe Departure & 8.6 & 15.0 & - \\
\hline Confidence & 54.5 & 44.4 & - \\
\hline \multirow[t]{2}{*}{ Darkness } & 84.4 & 76.9 & - \\
\hline & $\begin{array}{c}\text { No Drug Conviction } \\
\mathrm{n}=\mathbf{3 7 0} \\
\%\end{array}$ & $\begin{array}{c}\text { Drug Conviction \% } \\
n=104\end{array}$ & Sig. \\
\hline Fingerprint & 2.7 & 7.7 & - \\
\hline Reference to police & 7.4 & 15.4 & .03 \\
\hline \multirow[t]{2}{*}{ Blindfold } & 5.9 & 12.5 & - \\
\hline & $\begin{array}{c}\text { No Robbery } \\
\text { Conviction } n=401 \\
\% \\
\end{array}$ & $\begin{array}{c}\text { Robbery } \\
\text { Conviction } n=73 \\
\% \\
\end{array}$ & Sig. \\
\hline Forced Entry & 6.0 & 13.7 & .05 \\
\hline Semen Destruction & 6.5 & 13.7 & - \\
\hline Weapon & 22.4 & 34.2 & - \\
\hline \multirow[t]{2}{*}{ Theft } & 30.2 & 42.5 & - \\
\hline & $\begin{array}{c}\text { No Theft } \\
\text { Conviction } \mathrm{n}=256 \\
\%\end{array}$ & $\begin{array}{c}\text { Theft } \\
\text { Conviction } n=218 \\
\%\end{array}$ & Sig. \\
\hline Forced Entry & 3.5 & 11.5 & .007 \\
\hline Reference to Police & 5.9 & 12.8 & .035 \\
\hline Weapon & 20.3 & 28.9 & - \\
\hline \multirow[t]{2}{*}{ Theft } & 28.1 & 36.7 & - \\
\hline & $\begin{array}{c}\text { No Violence } \\
\text { Conviction } n=132 \\
\%\end{array}$ & $\begin{array}{c}\text { Violence } \\
\text { Conviction } n=342 \\
\%\end{array}$ & Sig. \\
\hline Victim's Phone Disabled & 1.2 & 5.3 & .014 \\
\hline
\end{tabular}


